\section{Note on looking time: Experimenter and instruction effects}

\author{
KENNETH S. KELEMAN \\ San Diego State College, San Diego, California 92115
}

In a recent article (Leckart, Gehres, \& Thornton, 1970), it was reported that the presence of $E$ inhibits Ss' looking time. The authors found a significant decrement in the E-present as compared to the E-absent condition and interpreted their results by suggesting that the decrease might be due to $\mathrm{Ss}^{\prime}$ fear that long looking times might reveal something self-intimidating to the $\mathrm{E}$.

Alternative explanations for this effect are provided by considering the presence of another person as a source of arousal. Evidence that the presence of other organisms increases arousal has been demonstrated on an infrahuman level (e.g., Thiessen, 1964; Christian \& Davis, 1964). decrease.
Assuming that looking at slides is a low-probability response, this approach would suggest that E's presence should reduce the duration of looking behavior.

\section{REFERENCES}

Assuming that this is also the case with humans and that $S$ is attempting to maintain an optimal level of cortical arousal, $S$ would need less environmental stimulation when $E$ was present to serve as a source of arousal. Hence, E's presence should be reflected in a looking time

A second explanation is provided by Zajonc (Zajonc, 1965; Zajonc \& Sales, 1966). This author accepts the presence of others as a source of arousal and combines this with a drive theory. He concludes that the presence of others increases dominant or high-probability responses, and inhibits subordinate or low-probability ones.
CHRISTIAN, J. J., \& DAVIS, D. E. Endocrines, behavior, and populations. Science, 1964, 146, 1550-1560.

LECKART, B. T., GEHRES, L., \& THORNTON, G. Looking time: Experimenter and instruction effects. Perception \& Psychophysics, 1970, 8, 54-56.

THIESSEN, D. D. Population density, mouse genotype, and endocrine function in behavior. Journal of Comparative \& Physiological Psychology, 1964, 57, 412-416.

ZAJONC, R. B. Social facilitation. Science, 1965 , $149,269.274$.

ZAJONC, R. B., \& SALES, S. M. Social facilitation of dominant and subordinate responses. Joumal of Experimental Social Psychology, 1966, 2, 160-168.

(Accepted for publication July 6, 1970.) 